Available online at GSC Online Press Directory

GSC Biological and Pharmaceutical Sciences

e-ISSN: 2581-3250, CODEN (USA): GBPSC2

Journal homepage: https://www.gsconlinepress.com/journals/gscbps

(RESEARCH ARTICLE)

\title{
Formulation and evaluation of gastro-retentive floating tablets of terbinafine
}

\author{
Kapil Jalodiya ${ }^{1}$, Sourabh Jain ${ }^{2,{ }^{*}}$ and Karunakar Shukla ${ }^{2}$ \\ ${ }^{1}$ Central India Institute of Pharmacy (CIIP), Indore (M.P.). \\ ${ }^{2}$ College of Pharmacy, Dr. A. P. J. Abdul Kalam University, Indore (M.P.).
}

Publication history: Received on 25 September 2020; revised on 05 October 2020; accepted on 10 October 2020

Article DOI: https://doi.org/10.30574/gscbps.2020.13.1.0310

\begin{abstract}
Gastro-retentive dosage forms enable prolonged and continuous input of the drug to the upper parts of the gastrointestinal tract and improve the bioavailability of medications those are characterized by a narrow absorption window. The purpose of this research was to develop a novel gastro retentive drug delivery system based on direct compression method for sustained delivery of active agent to improve the bioavailability, reduce the number of doses and to increase patient compliance. Gastro retentive floating tablets of terbinafine were prepared by direct compression method using altered concentrations of HPMC K4, HPMC K15 and PVP K30 as polymers. The prepared tablets of terbinafine were evaluated tablet hardness, uniformity of weight, friability, uniformity of content, in vitro buoyancy test, swelling index, in vitro dissolution study and stability study. All the compositions were resulted in adequate Pharmacopoeial limits. Compatibility studies was execution during FTIR shown that there was absence of probable chemical interaction between pure drug and excipients. The varying concentration of gas generating agent and polymers was found to affect on in-vitro drug release and floating lag time. In vitro drug release of floating gastro retentive tablet of terbinafine shown that the formulation F5 was found to be the best formulation as it releases $96.22 \%$ terbinafine in a controlled manner for an extended period of time (up to $480 \mathrm{~min}$ ). The release data was fitted to various mathematical models such as Higuchi, Korsmeyer-Peppas, First order and Zero order to evaluate the kinetics and mechanism of the drug release. Prepared floating tablets of terbinafine may prove to be a potential candidate for safe and effective controlled drug delivery over an extended period of time for gastro retentive drug delivery system.
\end{abstract}

Keywords: Terbinafine; Gastro-retentive; Floating tablet; Total floating time

\section{Introduction}

Oral sustained drug delivery system is complicated by limited gastric residence time. Rapid gastrointestinal transit can prevent complete drug release in the absorption zone and reduce the efficacy of administered dose, since the majority of drugs are absorbed in stomach or the upper part of small intestine [1,2]. Floating drug delivery offers several applications for drugs having poor bioavailability because of the narrow absorption window in the upper part of the gastrointestinal tract. It retains the dosage form at the site of absorption and thus enhances the bioavailability [3]. Terbinafine hydrochloride is a broad-spectrum antifungal activity against a wide variety of fungi [4-6]. It is an ally amine antifungal used in the treatment of jock itch and athletes foot. It is highly lipophilic in nature and tends to accumulate in skin and nails when applied topically and cause side effects like rash, irritation etc. Because of the size and porous polymeric structure of microsponges, they slowly release the active ingredient, thereby prevent excess build up in epidermis and dermis and reduce side effects. Terbinafine hydrochloride has Pharmacokinetic interactions with drugs that are substrates for CYP2D6 (e. g., tricyclic antidepressants, $\beta$-blockers, selective serotonin reuptake inhibitors

\footnotetext{
* Corresponding author: Dr. Sourabh Jain

College of Pharmacy, Dr. A. P. J. Abdul Kalam University, Indore (M.P.).

Copyright $(2020$ Author(s) retain the copyright of this article. This article is published under the terms of the Creative Commons Attribution Liscense 4.0.
} 
[SSRIs], and monoamine oxidase [MAO] inhibitors) [7, 8]. The objective of the present research work was to provide gastroretentive formulation that will provide once daily, sustained release dosage form of terbinafine.

\section{Material and methods}

\subsection{Materials}

Terbinafine $\mathrm{HCl}$ was obtained as a gift sample from Alkem Pharma, India. Hydroxypropyl methylcellulose (HPMC K4M, HPMC K15M) was procured from Meditab Specialities Pvt. Ltd., Satara. PVP K30 was purchased from S.D fine chemicals, Mumbai. Sodium bicarbonate, citric acid, magnesium stearate, talc were purchased from Mapromax, Life sciences Pvt. Ltd., Dehradun. Other solvents and chemicals used in the research were of LR grade. All the studies were carried in distilled water.

\subsection{Methods}

\subsubsection{Procedure for the determination of $\lambda_{\max }$}

Accurately weighed $100 \mathrm{mg}$ of pure drug and transferred to a $100 \mathrm{ml}$ volumetric flask containing $100 \mathrm{ml}$ of methanol and shaked to dissolve. Then $10 \mathrm{ml}$ of this solution was diluted to $100 \mathrm{ml}$ with methanol in a volumetric flask to obtain a solution of $10 \mu \mathrm{g} / \mathrm{ml}$ and the spectrum of this solution was run in 200-400 $\mathrm{nm}$ range in U.V. spectrophotometer (Shimadzu1800).

\subsubsection{Pre compression evaluation}

Flow properties and compressibility properties of powder mixture were evaluated by measurement of angle of repose, bulk density, tapped density, carr's index, and hausner ratio.

\section{Angle of repose $(\theta)$}

The angle of repose was determined by using fixed funnel method. The physical mixtures of drug with different excipients were prepared and the accurately weighed drug powder or its physical mixture was taken in a funnel. The height of the funnel was adjusted in such a way that the tip of the funnel just touches the apex of the heap of the drug powder. The powder was allowed to flow through the funnel freely onto surface. The angle of repose was calculated using the following equation.

$\theta=\tan -1(\mathrm{~h} / \mathrm{r})$

Where, $\mathrm{h}$ and $\mathrm{r}$ are the height and radius of the powder cone respectively.

Bulk density

Both loose bulk density (LBD) and tapped density (TBD) were determined were calculated using the following formulas.

LBD = Powder weight/volume of the packing

TBD $=$ Powder weight /tapped volume of the packing

Compressibility index

The compressibility index of the granules was determined by Carr's compressibility index.

Carr's index $(\%)=[(\mathrm{TBD}-\mathrm{LBD}) / \mathrm{TBD}] \times 100$.

Hausner's ratio

Hausner's ratio is an indirect index of ease of measuring the powder flow. It was calculated by the following formula [911].

Hausner's ratio $=$ Tapped density/Bulk density. 


\subsection{Formulation development of Tablets}

\subsubsection{Direct compression method}

Different tablets formulations (F1-F10) were prepared by direct compression technique using varying concentrations of different grades of polymers of HPMC \& ethyl cellulose with sodium bicarbonate, citric acid, Lactose and PVP K-30are geometrically mixed all the powders were passed through sieve. No \#80. Magnesium stearate and talc were finally added as glidant and lubricant respectively. The blend was directly compressed using tablet compression machine. The tablets were off white, round and flat [12]. The hardness of the tablets was kept constant. The detail of composition of each formulation is given in Table 1.

Table 1 Composition of different floating tablet formulations of terbinafine

\begin{tabular}{|c|c|c|c|c|c|c|c|c|c|c|}
\hline Ingredients & F1 & F2 & F3 & F4 & F5 & F6 & F7 & F8 & F9 & F10 \\
\hline Terbinafine & 250 & 250 & 250 & 250 & 250 & 250 & 250 & 250 & 250 & 250 \\
\hline HPMCK4 M, & 50 & 75 & 100 & - & - & - & - & - & - & 75 \\
\hline HPMCK15M & - & - & - & 50 & 75 & 100 & - & - & - & 25 \\
\hline Ethyl cellulose & - & - & - & - & - & - & 50 & 75 & 100 & 25 \\
\hline Lactose & 55 & 30 & 5 & 55 & 30 & 5 & 55 & 30 & 5 & 20 \\
\hline NaHCO3 & 75 & 50 & 50 & 50 & 50 & 50 & 50 & 50 & 50 & 50 \\
\hline Citric Acid & 50 & 50 & 50 & 50 & 50 & 50 & 50 & 50 & 50 & 50 \\
\hline PVP K-30 & 15 & 15 & 15 & 15 & 15 & 15 & 15 & 15 & 15 & 15 \\
\hline Talc & 2 & 2 & 2 & 2 & 2 & 2 & 2 & 2 & 2 & 2 \\
\hline Mg. Stearate & 3 & 3 & 3 & 3 & 3 & 3 & 3 & 3 & 3 & 3 \\
\hline Total & 500 & 500 & 500 & 500 & 500 & 500 & 500 & 500 & 500 & 500 \\
\hline
\end{tabular}

\subsection{Post- compression parameters $[13-15]$}

\subsubsection{Tablet Hardness}

The crushing strength $\mathrm{Kg} / \mathrm{cm}^{2}$ of prepared tablets was determined for 10 tablets of each batch by using Monsanto tablet hardness tester. The average hardness and standard deviation was determined.

\subsubsection{Uniformity of Weight}

Twenty tablets were individually weighed and the average weight was calculated. From the average weight of the prepared tablets, the standard deviation was determined.

\subsubsection{Friability}

Twenty tablets were weighed and placed in the Electro lab friabilator and apparatus was rotated at 25 rpm for 4 minutes. After revolutions the tablets were dedusted and weighed again.

$$
\% \mathrm{~F}=\left\{1-\left(\mathrm{W}_{\mathrm{t}} / \mathrm{W}\right)\right\} \times 100
$$

Where, $\% \mathrm{~F}=$ friability in percentage

$\mathrm{W}=$ Initial weight of tablet

$\mathrm{W}_{\mathrm{t}}=$ weight of tablets after revolution 


\subsubsection{Uniformity of Content}

Five randomly selected tablets were weighed and powdered. The powdered tablet equivalent to $20 \mathrm{mg}$ drug in one tablet was taken and transferred in a $250 \mathrm{ml}$ flask containing $100 \mathrm{ml}$ of $0.1 \mathrm{~N} \mathrm{HCl}(\mathrm{pH} 1.2)$. The flask was shaken on a flask shaker for 24 hours and was kept for 12 hours for the sedimentation of undissolved materials. The solution is filtered through Whatman filter paper. $10 \mathrm{ml}$ of this filtrate was taken and appropriate dilution was made. The samples were analyzed at $283 \mathrm{~nm}$ using UV visible spectrophotometer.

\subsection{In vitro Buoyancy Test}

The prepared tablets were subjected to in vitro buoyancy test by placing them in $250 \mathrm{ml}$ beaker containing $200 \mathrm{ml} 0.1 \mathrm{~N}$ $\mathrm{HCl}\left(\mathrm{pH} 1.2\right.$, temp. $37 \pm 0.5^{\circ} \mathrm{C}$ ). The time between introduction of the dosage form and its buoyancy in the medium and the floating durations of tablets was calculated for the determination of lag time and total buoyancy time by visual observation. The Time taken for dosage form to emerge on surface of medium called Floating Lag Time (FLT) or Buoyancy Lag Time (BLT) and total duration of time by which dosage form remain buoyant is called Total Floating Time (TFT)

\subsubsection{Swelling index}

Swelling of tablet excipients particles involves the absorption of a liquid resulting in an increase in weight and volume. Liquid uptake by the particle may be due to saturation of capillary spaces within the particles or hydration of macromolecule. The liquid enters the particles through pores and bind to large molecule; breaking the hydrogen bond and resulting in the swelling of particle. The extent of swelling can be measured in terms of weight gain by the tablet. Each tablet from all formulations pre-weighed and allowed to equilibrate with $0.1 \mathrm{~N} \mathrm{Hcl}(\mathrm{pH}-1.2)$ for $5 \mathrm{hr}$, was then removed, blotted using tissue paper and weighed. The swelling index was then calculated using the formula:

$$
\text { Swelling index } \mathrm{WU}=\frac{\left(\mathrm{W}_{1}-\mathrm{W}_{0}\right)}{\mathrm{W}_{0}} \times 100
$$

Where, $\mathrm{W}_{\mathrm{t}}=$ Weight of tablet at time $\mathrm{t}, \mathrm{W}_{0}=$ Initial weight of tablet

\subsubsection{In vitro Dissolution Study}

In Vitro dissolution study was carried out using USP II apparatus in $900 \mathrm{ml}$ of $0.1 \mathrm{~N} \mathrm{HCl}$ (pH 1.2) for 8 hours. The temperature of the dissolution medium was kept at $37 \pm 0.5^{\circ} \mathrm{C}$ and the paddle was set at $50 \mathrm{rpm} .10 \mathrm{ml}$ of sample solution was withdrawn at specified interval of time and filtered through Whatman filter paper. The absorbance of the withdrawn samples was measured at $\lambda_{\max } 283 \mathrm{~nm}$ using UV visible spectrophotometer.

Mathematical treatment of in-vitro release data

The quantitative analysis of the qualities got in dissolution/release tests is simpler when mathematical formulas that express the dissolution comes about as an element of a portion of the measurement frames attributes are utilized.

\section{Zero-order kinetics}

The pharmaceutical dosage frames following this profile release a similar measure of medication by unit of time and it is the ideal method of medication release keeping in mind the end goal to accomplish a pharmacological prolonged action. The following relation can, in a simple way, express this model:

$$
Q_{t}=Q_{0}+K_{0} t
$$

Where $Q_{t}$ is the amount of drug dissolved in time $t, Q_{o}$ is the initial amount of drug in the solution (most times, $Q_{0}=0$ ) and $\mathrm{K}_{\mathrm{o}}$ is the zero order release constant.

First-order kinetics

The following relation expresses this model:

$$
\log Q_{t}=\log Q_{0}+\frac{K_{1} t}{2.303}
$$


Where $\mathrm{Q}_{\mathrm{t}}$ is the amount of drug dissolved in time $\mathrm{t}, \mathrm{Q}_{\mathrm{o}}$ is the initial amount of drug in the solution and $\mathrm{K}_{1}$ is the zero order release constant.

Along these lines a graphic of the decimal logarithm of the released measure of drug versus time will be linear. The pharmaceutical dosage shapes following this dissolution profile, for example, those containing water-solvent drugs in permeable frameworks, discharge drug in a way that is corresponding to the measure of drug staying in its inside, in such way, that the measure of drug released by unit of time reduce.

Higuchi model

Higuchi built up a few theoretical models to ponder the arrival of water-solvent and low dissolvable medications in semi-strong or potentially strong grids. Mathematical expressions were acquired for sedate particles scattered in a uniform grid acting as the diffusion media. The simplified Higuchi model is expressed as:

$$
\mathrm{Q}=\mathrm{K}_{\mathbf{H}} \mathbf{t}^{\mathbf{1} / 2}
$$

Where $\mathrm{Q}$ is the amount of drug released in time $\mathrm{t}$ and $\mathrm{K}_{\mathrm{H}}$ is the Higuchi dissolution constant. Higuchi model describes drug release as a diffusion process based in the Fick's law, square root time dependent. This relation can be utilized to portray the drug dissolution from a few kinds of modified release pharmaceutical dosage structures, for example, transdermal systems and matrix tablets with water-dissolvable drugs.

Korsmeyer-Peppas model

Korsmeyer et al. used a simple empirical equation to describe general solute release behaviour from controlled release polymer matrices:

$$
\frac{\mathrm{M}_{\mathbf{4}}}{\mathrm{M}_{\mathbf{w}}}=\mathbf{a t}^{n}
$$

where $M_{t} / M_{\infty}$ is fraction of drug released, a is kinetic constant, $t$ is release time and $n$ is the diffusional exponent for drug release. ' $n$ ' is the slope value of $\log \mathrm{M}_{\mathrm{t}} / \mathrm{M}_{\infty}$ versus $\log$ time curve. Peppas stated that the above equation could adequately describe the release of solutes from slabs, spheres, cylinders and discs, regardless of the release mechanism. Peppas used this $\mathrm{n}$ value in order to characterize different release mechanisms, concluding for values for a slab, of $n=0.5$ for fickian diffusion and higher values of $n$, between 0.5 and 1.0, or $n=1.0$, for mass transfer following a non-fickian model. In case of a cylinder $n=0.45$ instead of 0.5 , and 0.89 instead of 1.0. This equation can only be used in systems with a drug diffusion coefficient fairly concentration independent. To the determination of the exponent $n$ the portion of the release curve where $M_{t} / M_{\infty}<0.6$ should only be used. To use this equation it is also necessary that release occurs in a onedimensional way and that the system width-thickness or length-thickness relation be at least 10 . A modified form of this equation was developed to accommodate the lag time $(I)$ in the beginning of the drug release from the pharmaceutical dosage form:

$$
\frac{\mathrm{M}_{\mathrm{r} l}}{\mathrm{M}_{\mathbf{w}}}=\mathbf{a}(\mathrm{t}-l)^{n}
$$

When there is the possibility of a burst effect, $b$, this equation becomes:

$$
\frac{M_{4}}{M_{\mathbf{w}}}=a t^{n}+b
$$

In the absence of lag time or burst effect, l and bvalue would be zero and only $\mathrm{at}^{n}$ is used. This mathematical model, also known as Power Law, has been used very frequently to describe release from several different pharmaceutical modified release dosage forms [16-20]. 


\section{Stability Studies}

The success of an effective formulation can be evaluated only through stability studies. The purpose of stability is to obtain a stable product which assures its safety and efficacy up to the end of shelf life at defined storage conditions and peak profile. ICH specifies the length of study and storage conditions.

Long term testing $\quad-25{ }^{\circ} \mathrm{C} \pm 2{ }^{\circ} \mathrm{c} / 60 \% \mathrm{RH} \pm 5 \%$ for 12 months.

Accelerated testing $-42^{\circ} \mathrm{C} \pm 2^{\circ} \mathrm{C} / 75 \% \mathrm{RH} \pm 5 \%$ for 6 months.

The mixture of drug and the excipients and three tablets of each formulation were placed in humidity chamber at, $40^{\circ} \mathrm{C}$, and $2-8^{\circ} \mathrm{C}$ for 30 days. After the completion of one month the samples were analyzed visually for any color changes due to physical and chemical interaction within excipients and with the drug. The percentage drug content in all the tablets was determined after specified period.

\section{Results and discussion}

The drug terbinafine is White fine crystalline powder having melting point about $204-208^{\circ} \mathrm{C}$. It is freely soluble methanol and dichloromethane, soluble in ethanol, and slightly soluble in water. It is highly hydrophobic and tends to accumulate in hair, skin, nails, and fatty tissue. The $\lambda$ max of terbinafine was found to be $283 \mathrm{~nm}$ by using U.V. spectrophotometer (Simadzu 1800) in linearity range 5-30 $\mathrm{gg} / \mathrm{ml}$ Fig.1 \& 2. Tablet powder blend was subjected to various pre-formulation parameters Table 2 . The angle of repose values indicates that the powder blend has good flow properties. The bulk density of all the formulations was found to be in the range of 0.521 to 0.580 (gm/ ml) showing that the powder has good flow properties. The tapped density of all the formulations was found to be in the range of 0.513 to 0.661 showing the powder has good flow properties. The compressibility index of all the formulations was found to be ranging between 6.19to10.34 which shows that the powder has good flow properties. All the formulations have shown the Hauser's ratio ranging between 1.02to 1.13 indicating the powder has good flow properties. Terbinafine tablet quality control tests such as weight variation, hardness and friability, thickness, drug content and drug release studies in different media were performed on the compression tablet. All the parameters such as weight variation, hardness, friability, thickness and drug content were found to be within limits Table 3 . In the present study 10 formulations with variable concentration of polymers (HPMC K4, K 15) were prepared by direct compression method and evaluated for physicochemical properties. The results of buoyancy lag time, total floating time, swelling indexand in vitro drug release was given in Table 4-6.The results indicated that optimizes formulation $\mathrm{F} 5$ on immersion in $0.1 \mathrm{~N} \mathrm{HCl}$ at $37 \pm 0.5^{\circ} \mathrm{C}$ tablets immediately and remain buoyant upto 480 minwithout disintegration. These 2 factors are essential for tablets to acquire density< 1 , so that it remains buoyant on the gastric fluids. The in vitro drug release data of the optimized formulation was subjected to goodness of fit test by linear regression analysis according to zero order, first order kinetic equation, higuchi's and korsmeyer's models in order to determine the mechanism of drug release. When the regression coefficient values of were compared, it was observed that ' $r$ ' values of higuchi model was maximum i.e. 0.9935 hence indicating drug release from formulations was found to follow higuchi model release kinetics Table 7. Stability study was carried out for one month on mixture of drug with excipients and the prepared tablets formulation. After one month the samples were analyzed for the changes in physical appearance and drug content. No change in the physical appearance of the mixtures and the tablets was found Table 8.

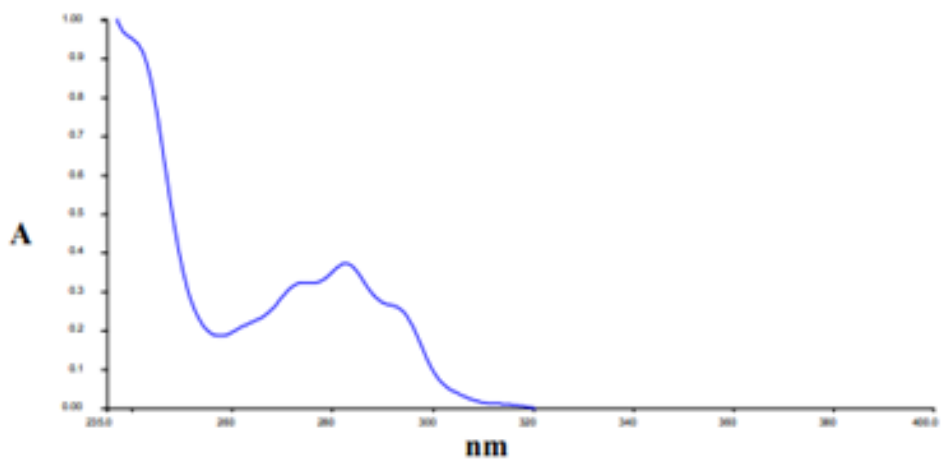

Figure1 UV Scan of terbinafine $\mathrm{HCl}$ in methanol 


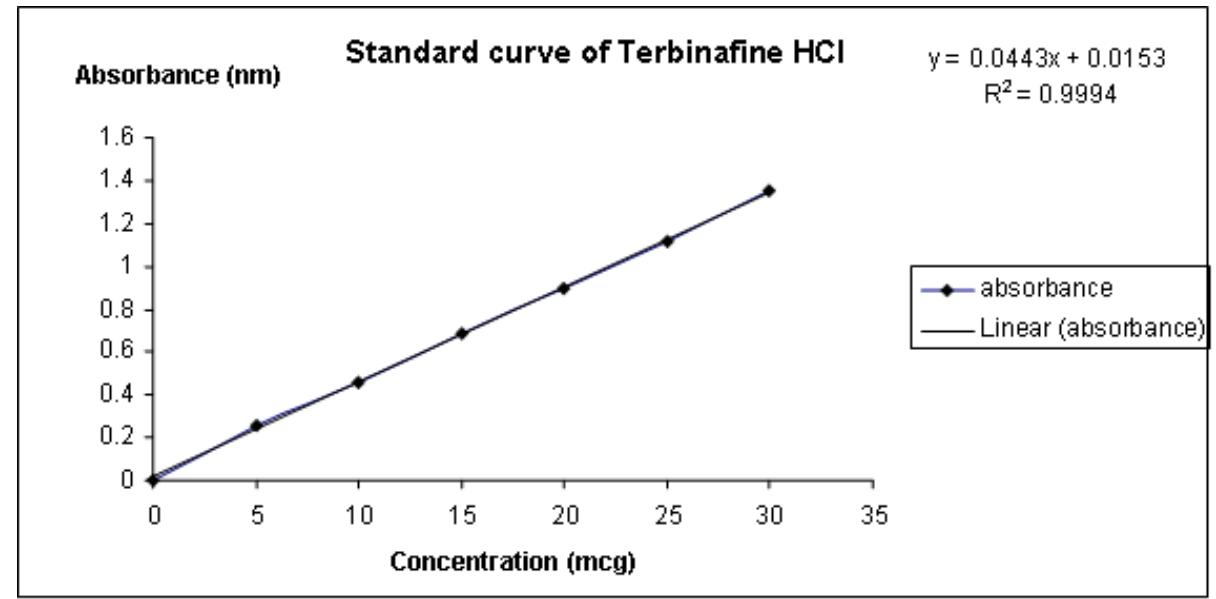

Figure 2 Standard curve of terbinafine $\mathrm{HCl}$ at $\lambda \max 283 \mathrm{~nm}$

Table 2 Result of pre-compression properties of terbinafine GRF tablets

\begin{tabular}{|c|c|c|c|c|c|}
\hline Parameters & Bulk density & $\begin{array}{c}\text { Tapped } \\
\text { density }\end{array}$ & Carr's index & Hausner's ratio & $\begin{array}{c}\text { Angle of } \\
\text { repose }\end{array}$ \\
\hline F1 & 0.521 & 0.585 & 10.34 & 1.12 & $22.5^{\text {o }}$ \\
\hline F2 & 0.533 & 0.597 & 10.16 & 1.13 & $24.3^{0}$ \\
\hline F3 & 0.562 & 0.611 & 8.19 & 1.08 & $21.8^{0}$ \\
\hline F4 & 0.543 & 0.583 & 6.89 & 1.06 & $21.3^{0}$ \\
\hline F5 & 0.582 & 0.661 & 9.37 & 1.13 & $24.5^{0}$ \\
\hline F6 & 0.566 & 0.613 & 8.19 & 1.08 & $21.3^{0}$ \\
\hline F7 & 0.544 & 0.593 & 8.19 & 1.09 & $20.9^{0}$ \\
\hline F8 & 0.580 & 0.633 & 7.93 & 1.07 & $22.1^{0}$ \\
\hline F9 & 0.548 & 0.589 & 6.82 & 1.02 & $23^{0}$ \\
\hline F10 & 0.546 & 0.513 & 6.19 & 1.16 & $24^{0}$ \\
\hline
\end{tabular}

Table 3 Results of post compression properties of terbinafine GRF tablets

\begin{tabular}{|c|c|c|c|c|}
\hline Parameters & Weight variation & Hardness & Friahility (\%) & Drug \\
\hline Batch No. & weight variation & $(\mathrm{kg} / \mathrm{cm} 2)$ & Friability (\%) & Content (\%) \\
\hline $\mathrm{F} 1$ & Pass & 5.6 & 0.51 & 98.5 \\
\hline $\mathrm{F} 2$ & Pass & 5.9 & 0.63 & 99.1 \\
\hline F3 & Pass & 6.2 & 0.69 & 98.1 \\
\hline $\mathrm{F} 4$ & Pass & 6.0 & 0.58 & 99.4 \\
\hline F5 & Pass & 6.4 & 0.69 & 99.5 \\
\hline F6 & Pass & 6.9 & 0.72 & 96.2 \\
\hline F7 & Pass & 7.2 & 0.53 & 97.3 \\
\hline F8 & Pass & 7.4 & 0.49 & 98.4 \\
\hline F9 & Pass & 7.6 & 0.41 & 99.2 \\
\hline F10 & Pass & 7.5 & 0.46 & 98.3 \\
\hline
\end{tabular}


Table 4 Results of in-vitro buoyancy study of terbinafine

\begin{tabular}{|c|c|c|}
\hline Batch & Buoyancy Lag Time(sec.) & Total Floatation time(hr.) \\
\hline F1 & 100 & 8 \\
\hline F2 & 115 & 8 \\
\hline F3 & 180 & 8 \\
\hline F4 & 105 & 8 \\
\hline F5 & 120 & $>12$ \\
\hline F6 & 155 & $>12$ \\
\hline F7 & 165 & $>12$ \\
\hline F8 & 170 & $>12$ \\
\hline F9 & 180 & $>12$ \\
\hline F10 & 178 & $>12$ \\
\hline
\end{tabular}

Table 5 Swelling index of tablets of batches F1 to F10

\begin{tabular}{|c|c|c|c|c|c|c|}
\hline \multirow{2}{*}{ Batch } & \multicolumn{6}{|c|}{ TIME (HRS) } \\
\hline & $\mathbf{0}$ & 1 & 2 & 3 & 4 & 5 \\
\hline F1 & 0 & 41.25 & 54.48 & 65.32 & 70.05 & 88.12 \\
\hline $\mathrm{F} 2$ & 0 & 49.25 & 61.54 & 72.90 & 82.37 & 92.54 \\
\hline F3 & 0 & 35.21 & 48.92 & 55.76 & 69.52 & 78.2 \\
\hline $\mathrm{F} 4$ & 0 & 36.09 & 47.45 & 55.32 & 67.12 & 78.97 \\
\hline F5 & 0 & 45.73 & 59.76 & 67.72 & 81.26 & 91.60 \\
\hline F6 & 0 & 32.55 & 43.35 & 57.32 & 62.45 & 74.09 \\
\hline F7 & 0 & 36.76 & 48.98 & 59.54 & 67.06 & 81.78 \\
\hline F8 & 0 & 28.45 & 42.78 & 53.87 & 61.58 & 75.02 \\
\hline F9 & 0 & 43.06 & 57.96 & 65.32 & 78.34 & 92.09 \\
\hline F10 & 0 & 36.19 & 43.44 & 51.12 & 60.02 & 77.79 \\
\hline
\end{tabular}

Table 6 In vitro release profile of formulation F5

\begin{tabular}{|c|c|c|c|c|c|c|}
\hline S.no. & $\begin{array}{c}\text { Time } \\
\mathbf{( m i n )}\end{array}$ & Root time & Log time & $\begin{array}{c}\text { Cumulative } \\
\text { Conc. }\end{array}$ & $\begin{array}{c}\text { Cumulative } \\
\text { \% release }\end{array}$ & $\begin{array}{c}\text { Log } \\
\text { Cumulative } \\
\text { Release }\end{array}$ \\
\hline 1 & 0.000 & 0.000 & 0.000 & 0.000 & 0.000 & 0.000 \\
\hline 2 & 30.000 & 5.477 & 1.477 & 5.058 & 25.29 & 1.402983 \\
\hline 3 & 60.000 & 7.746 & 1.778 & 8.108 & 40.54 & 1.607905 \\
\hline 4 & 120.000 & 10.954 & 2.079 & 11.235 & 56.17 & 1.749536 \\
\hline 5 & 180.000 & 13.416 & 2.255 & 12.676 & 63.37 & 1.801937 \\
\hline 6 & 240.000 & 15.492 & 2.380 & 15.377 & 76.88 & 1.885841 \\
\hline 7 & 300.000 & 17.321 & 2.477 & 16.377 & 81.88 & 1.913215 \\
\hline 8 & 360.000 & 18.974 & 2.556 & 17.850 & 89.25 & 1.950611 \\
\hline 9 & 420.000 & 20.494 & 2.623 & 18.603 & 93.01 & 1.968549 \\
\hline 10 & 480.000 & 21.909 & 2.681 & 19.045 & 96.22 & 1.97875 \\
\hline
\end{tabular}


Table 7 Regression analysis data of terbinafine floating tablets

\begin{tabular}{|c|c|c|c|c|}
\hline \multirow{2}{*}{ Batch } & Zero Order & First Order & Higuchi & Korsmeyer-Peppas \\
\cline { 2 - 5 } & $\mathbf{R}^{\mathbf{2}}$ & $\mathbf{R}^{\mathbf{2}}$ & $\mathbf{R}^{\mathbf{2}}$ & $\mathbf{R}^{\mathbf{2}}$ \\
\hline F5 & 0.8934 & 0.476 & 0.9935 & 0.9698 \\
\hline
\end{tabular}

Table 8 Percentage drug contents for the different formulations

\begin{tabular}{|c|c|c|}
\hline \multicolumn{3}{|c|}{ Percentage (\%) Drug Content } \\
\hline & Initial & After one month \\
\hline F1 & 98.5 & 98.2 \\
\hline F2 & 99.1 & 99.0 \\
\hline F3 & 98.1 & 97.6 \\
\hline F4 & 99.4 & 99.0 \\
\hline F5 & 99.5 & 98.5 \\
\hline F6 & 96.2 & 96.1 \\
\hline F7 & 97.3 & 96.5 \\
\hline F8 & 98.4 & 97.7 \\
\hline F9 & 99.2 & 98.9 \\
\hline F10 & 98.3 & 93.4 \\
\hline
\end{tabular}

\section{Conclusion}

In the present work, it can be concluded that the terbinafine floating tablets can be an innovative and promising approach for the delivery of terbinafine. The optimized formulation F5 contains HPMC K15, PVP K-30 and a gas generating agent. The optimized formulation F5 showed drug release of $96.22 \%$ within $480 \mathrm{~min}$. The In vitro drug release data of the optimized formulation was subjected to goodness of fit test by linear regression analysis according to zero order, first order kinetic equation, higuchi's, and korsmeyer's models in order to determine the mechanism of drug release. When the regression coefficient values of were compared, it was observed that ' $r$ ' values of higuchi's was maximum i.e. 0.9935 hence indicating drug release from formulations was found to follow higuchi's release kinetics.

\section{Compliance with ethical standards}

\section{Acknowledgments}

No funding has been received to support this work. No funds have been received, to cover the costs to publish in open access.

\section{Disclosure of conflict of interest}

The authors declare no conflict of interest, financial or otherwise.

\section{References}

[1] Choi BY, Fark HJ, Hwang SJ, Park JB. Floating in situ gelling system of acetohydroxamic acid for clearance of H. pylori. Drug Dev Ind Pharm. 2008; 34:577-87.

[2] Mahant S, Nasa P. Floating drug delivery system using Methocel K100M and E50: formulation and characterization. Acta Pharma Sci 2011; 53:57-65. 
[3] Kaza R, Usharani E, Nagaraju R, Haribabu R, Reddy PVS. Design and evaluation of sustained release floating tablets for the treatment of gastric ulcers. J Pharm Sci Res 2009; 1(4):81-7.

[4] Alberti I, Kalia YN, Naik A, Bonny JD, Guy RH. In vivo assessment of enhanced topical delivery of terbinafine to human stratum corneum. J Controlled Release 2001; 71: 319-27.

[5] Balfour JA, Faulds D. Terbinafine: a review of its pharmacodynamic and pharmacokinetic properties and therapeutic potential in superficial mycoses. Drugs 1992; 43:259-84.

[6] Kazakov PV, Golosov SN. A simple method for obtaining terbiınafine hydrochloride. Pharm Chem J 2004; 38:34=6.

[7] Novartis. Lamisil (terbinafine) oral granules prescribing information. East Hanover. NJ; 2007.

[8] Novartis. Lamisil (terbinafine hydrochloride) tablets prescribing information. East Hanover. NJ; 2005.

[9] Patrick J. Sinko, Physical Pharmacy and Pharmaceutical Sciences, Lippincott Williams and Wilkins, 5th Edition, 2006.

[10] Chein YW. Novel drug delivery systems, Marcel Dekker, INC, 2nd edition, 1992, 140.

[11] Liberman HA, Lachman L, Schwartz JB. Pharmaceutical dosage forms: Tablets, 3rd edition, Marcel Dekker, New York, 1990.

[12] Ambati BR, Samyuktha Rani B, Eswar Tony D and Sivanaga Raja D. Aceclofenac Floating Tablets- A Promising Suatained Release Dosage Form. Int J Drug Develop Res 2011; 3: 290-300.

[13] Rajesh K, Usharani E, Nagaraju R. Design and evaluation of sustained release floating tablets for the treatment of gastric ulcer, J Pharma Sci Res 2009;1(4): 81-87.

[14] Mahajan S, Choukse R, Jain S, Shukla K. Floating microspheres of MET-HCl. Int J Pharm Sci Med 2019; 4(9): 130 .

[15] Ritger PL, Peppas NA. A Simple equation for description of solute release fickian and anomalous release from swellable devices, J Controlled Release. 1987; 5(1): 37-42.

[16] Brahamankar DM, Jaiswal SB. Biopharmaceutics and pharmacokinetics e a treatise, pharmacokinetics: basic consideration. 2nd ed. Vallabh Prakashan; 2009. pp. $240 \mathrm{e} 3$.

[17] Higuchi T. Mechanism of sustained action medication, theoretical analysis of rate of release of solid drugs dispersed in solid matrices. J Pharm Sci 1963; 52:1145-9.

[18] Korsmeyer RW, Gumy R, Doelker E, Buri P, Peppas NA. Mechanism of solute release from porous hydrophilic polymer. Int J Pharm. 1983; 15:25-35.

[19] Krithika Lashkari, Dr. Sourabh Jain, Dr. Karunakar Shukla "Formulation and Evaluation of oral colon targeted tablets of 5-Amino Salicylic Acid and Camylofine dihydrochloride" Universe International Journal of Interdisciplinary Research. 2020; 1(2); 459-61.

[20] Jain S., Yadav S.K. and Patil U.K. Preparation and Evaluation of Sustained Release Matrix Tablet of Furosemide Using Natural Polymers Research J. Pharm. and Tech. 2008; 1(4); 374-76.

\section{Author's short biography}

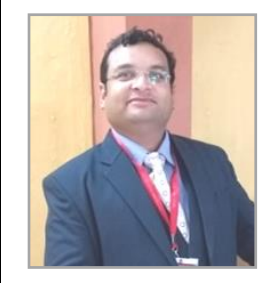

\section{Dr. Sourabh Jain}

Author has completed his UG (2003) \& PG (2008) in Pharmacy from VNS Institute of Pharmacy, Bhopal (MP) \& PhD (Pharmaceutics) from Banasthali Vidyapith, Banasthali (Rajasthan). Also qualified GATE 2006 and completed HDCA (diploma) from AISECT. Author is having academic experience of 08 years and research experience of 06 years. He has published 36+ research and review articles in international and national journals. He was worked as Preclinical Scientist in Pinnacle Biomedical Research Institute (PBRI), Bhopal (MP) from 2012 to 2018 and presently worked as Professor in Dr APJ Abdul Kalam University, Indore (MP) since 2018 and area of interest is preclinical research, and NDDS formulation development. Serves as joint Secretary, in Indian Pharmaceutical Graduates' Association (IPGA) M.P. State Branch, Indore MP. Active reviewer and editorial member of various journals. 